\title{
Foreign Area Studies and Their Effect \\ On Library Development
}

\author{
By PHILIP J. McNIFF
}

Area study programs, as now understood, are for the most part a post-World War II development. While it is true that long-standing programs of classical studies in many of our universities had all the interdisciplinary aspects of the contemporary area studies program-including studies in history, anthropology, political science, geography, fine arts, language and literature-these programs were clearly defined, historically limited, and based on our common Graeco-Roman civilization. The same cannot be said for the non-Western civilizations. While classical studies have frequently been treated in a broad manner, the basic programs in most of our institutions have been based on departmental or single disciplinary considerations.

Our present area programs were greatly stimulated, though not solely caused, by the needs of World War II. A limited number of active programs has existed since the early 1930's, including Michigan's Program in Oriental Civilization and the University of California's (Berkeley) Latin American Program. However, the lack of language training and inadequate knowledge of the history, geography, politics, and cultures of the nations engaged in World War II required the immediate establishment of training and research programs on an area or regional basis. The Army specialized training programs, the civil affairs training schools for area and language studies, and the Military Intelligence Service language schools were organized to meet these needs. These programs, plus other governmental efforts to harness scientific and scholarly resources in behalf of the defense effort certainly
Mr. McNiff is Associate Librarian of Harvard College.

gave impetus to the postwar area programs which developed in our institutions.

Wendell C. Bennett, in his preface to Robert B. Hall's Area Studies: With Special Reference to their Implications for Research in the Social Sciences, May 1947, stated: "Only recently have they [area studies] entered the universities, and many still doubt that they have enough solidity, enough scholastic core, to occupy a permanent place in higher education." $1 \mathrm{He}$ also reported that: "The wartime experience of the [Ethnogeographic] Board [established on the recommendations of the area committees of ACLS, SSRC, National Research Council and the Smithsonian Institution] pointed up clearly the woeful lack of area experts, however defined; the limited facilities for area training; the inadequate knowledge about many areas; and the vagueness of the criteria for area information and of the definitions for area reports." 2

Although significant progress has been made in the past fifteen years in developing programs of area studies both in the interest of scholarship and the national welfare, the full impact of area programs has been felt by relatively few institutions. Before examining some of the implications of these programs, let us examine the area studies situation as it existed in 1947.

1 Hall, Area Studies: With Special Reference to their Implications for Research in the Social Sciences. Pamphlet 3. (New York: Social Science Research Council, 1947), p. iii.

${ }^{2}$ Ibid, p. iii. 
Hall's summary states: "We appear to be best equipped in the Latin American field, although as previously mentioned, there seems to be the beginning of a slackening of interest comparable to that which followed World War I. There are at least six institutions which have well developed programs at one or more levels, good staffs, and considerable library facilities. Here are included, listed alphabetically, California at Berkeley, Duke-North Carolina . . . , Michigan, New Mexico, Northwestern, and Texas.

"The Far East is relatively well off. Harvard, Michigan, Washington, and Yale have considerable resources and a good start. California at Berkeley, Chicago, Columbia, and Stanford have important resources and some beginnings. A half-dozen others have ambitions and some promise....

"In the Russian field Columbia at the moment holds a near monopoly in its Russian Institute. . . . Stanford, well equipped in some respects, is developing a center for postdoctoral and research work, Yale has in operation a Russian area program. ... Harvard has an excellent library and some strength in personnel, and is doing a great deal of very energetic planning. Some strength in language and literature is scattered through the universities of the country and there are a few able but isolated social scientists. All in all, qualified personnel in the Russian field is decidedly short of the need. . . .

"The Near East is completely neglected and there are few scholars in the country who know anything about the area except in the field of languages. Princeton has both plans and some resources on this area.

"It would be most difficult, if not impossible, to build a single major center on Africa. Pennsylvania, to be sure, has its African Institute . . . but it is badly understaffed. Fisk, too, has an institute but it is still in a highly rudi- mentary stage. There are healthy developments at Northwestern in African anthropology and at Minnesota in North African languages.

"In the case of both India and Indonesia the lack of personnel is most appalling. Probably no center on either area could be adequately staffed with American personnel. No serious attempt to develop either area was encountered. ..."3

It is perfectly obvious from the foregoing summary that our accomplishments in area studies in 1947 left much to be desired. The critical needs then, as now, are competent area specialists, adequate library resources, and well supported programs. The criteria set up by the SSRC's Committee on World Area Research for the ideal integrated program are:

1. Official university recognition and support of the program;

2. Adequate library resources for teaching and research in the area;

3. Competent instruction in the principle languages of the area;

4. Offerings in at least five pertinent subjects in addition to language instruction;

5. Some specific mechanisms for integrating the area studies;

6. An area research program;

7. Emphasis on the contemporary aspects of the area.

All seven criteria have relevance to library activities supporting area programs. While integrated area programs established during the past fifteen years are not of uniform quality and while some are more formally organized than others, all have measured up, at least partially, to the above criteria. A statistical account of the increase in the number of area programs in our universities is not of itself conclusive evidence of improvement, yet it does indicate in some measure the growth and vitality

Ibid, pp. 83-85. 
of this type of program. In 1946, there were but thirteen operating area programs: four for East Asia; six for Latin America; and three for Russia and Eastern Europe. There were no programs for Africa, South and Southeast Asia or the Near East. In 1962 there were one hundred thirty-five programs in sixty-two universities, including thirteen programs for Africa, twelve for South and Southeast Asia, and seventeen for the Near East.

This growth certainly is indicative of the acceptance by university administrations and faculties of area studies programs as a standard and integral part of American higher education. President Griswold of Yale, in his 1961-62 report, paid special attention to Yale's ten-year plan for international and foreign area studies; he noted that: "Perhaps the most telling fact of all, however, is that whereas in 1931 there were offered in Yale College, excluding languages, exactly four courses dealing with the nonWestern world, and in their four years at Yale, exactly one hundred and two members of the Class of 1931 elected these courses, today there are thirty-four such courses with an average student enrollment of 2,363." 4

Our libraries' efforts to meet the needs of the various area study programs have been substantial. An accurate measure of the extent of these efforts would require a series of surveys on each of the areas similar to the Ruggles-Mostecky survey of Russian and East European Publications in the Libraries of the United States. ${ }^{5}$ The fact that the term 'area studies' has not yet found its way into Library Literature may be indicative of the work that needs to be done in assessing the library implications of this postwar academic phenomenon which enjoys the concern and support

\footnotetext{
4President's Report, 1961-1962. (New Haven: Yale University, 1962), p. 21.

5 Melville J. Ruggles and Vaclav Mostecky, Russian and East European Publications in the Libraries of the Und East European Putes. (New York: Columbia, 1960).
}

of foundations, scholarly associations, and the government. It was also somewhat disturbing to find that a check of the volumes of Library Literature for the past decade revealed no entries for African, Slavic, Middle Eastern or Far Eastern studies, although there were a handful of entries under Latin American Cooperative Acquisitions Project. I do not mean to imply that one cannot find material on area studies in library publications, but the absence of specific references to accepted terminology may have some significance.

Area programs have budgetary and financial implications for our libraries; these involve personnel, book selection, cataloging, reference services, and interlibrary, as well as international, cooperation. Every study of area programs, whether general or specific, emphasizes that a good library collection is a basic requirement, and that adequate support must be made available so that library resources can be built up. The Hall survey indicated that few libraries had collections sufficient for serious study of major areas and, although it has been said time and again, it is still necessary to stress that availability and development of library resources should be given first consideration before a new program is started. It takes time and money to build up a collection adequate to support an area study program. This is true even when one starts with a good general basic collection.

The magnitude of the problem facing our libraries in the development of area resources was indicated by Richard $\mathrm{H}$. Logsdon in his talk on The Need for Research in the Library Field at the fortysixth Annual Conference of Eastern College Librarians two years ago. He stated: "Our faculties are demanding more breadth and depth of collecting; not many years ago our Slavic acquisitions were less than 1 per cent of the total. Today, approximately one book in every fifteen is related to this new area of con- 
cern, but we must be concerned with China, too, and India and Pakistan and the whole Middle Eastern area and East Central Europe and now Africa, while at the same time [and this is most important] not lessening our representation of Western European and, of course, American materials. This is bringing us new problems in range and diversity of languages, interpolation of bibliographical information into our catalogs, and is even raising havoc with some of our classification systems." 6

The rapid growth of Columbia's Slavic collection is typical of the development of many of our university libraries in this important area. The Slavic collection of the Harvard University library contained 65,000 titles in 1957 and by 1962 had increased to 150,000 titles; the expenditures for the past year for the Harvard University library, in this field totaled approximately $\$ 178,000$. The college library has added well over fifty thousand volumes in the past five years, and a special Slavic section, made up of three librarians, one intern, five and onehalf clerical assistants, plus student help, is organized to handle the selection, acquisition, and cataloging of Slavic ma-

- Logsdon, "The Need for Research in the Library Field," CRL, XXII (1961), 364. terials and to give reference assistance as needed to supplement the services offered in the reference department. This staff can be contrasted with the one fulltime and one part-time person working on Slavic materials in 1948. Another example of accelerated activity in this field is offered by the University of Illinois library which, in the past year, acquired almost one-third of its entire Slavic collection of fifty thousand volumes. Illinois, two years ago, established a special Slavic section in its library in response to the needs of its Center for Russian Language and Area Studies. It now has a staff of seven bibliographers and catalogers, two clerical assistants, and several part-time student assistants; it "is charged with bringing the Slavic holdings of this library .... up to the standard of the library's long established collections." 7

Similar developments are taking place on many campuses in regard to the other areas of the world. The Nunn-Tsien Survey of Far Eastern Resources in American Libraries noted in 1957: "Since the end of World War II, Harvard has almost doubled its Far Eastern holdings, and the Library of Congress and the

Tnnual Report, University of Illinois Library, 1961-1962.

DEPARTMENT OF STATE SURVEY REPORTS

Programs in Universities

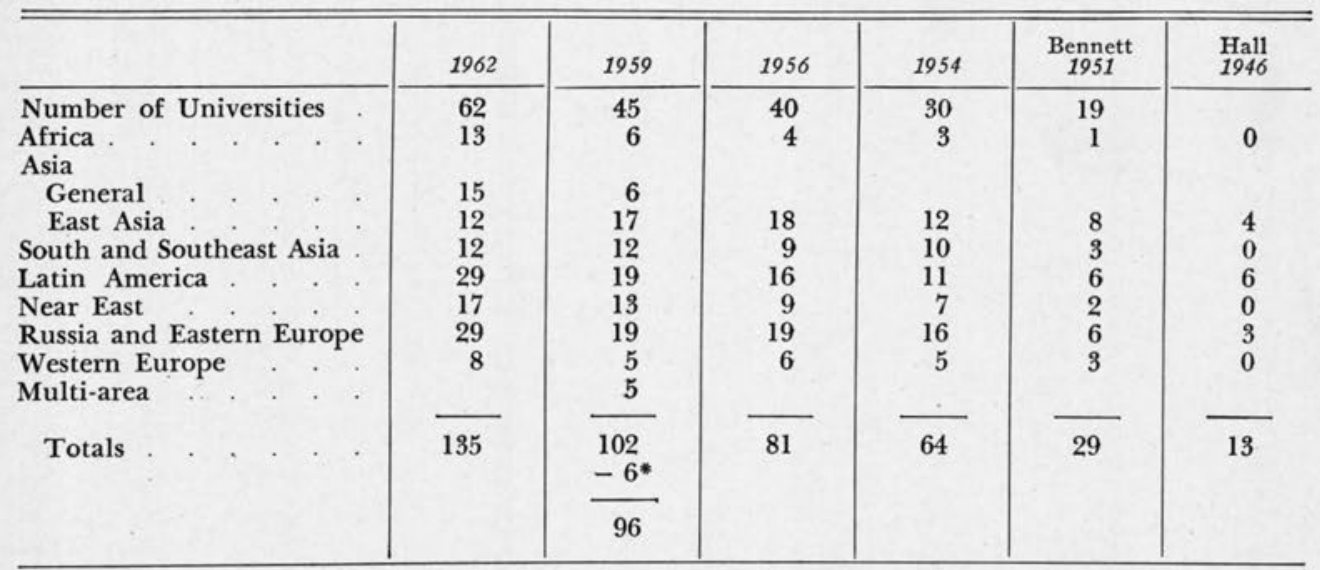

* Six programs provided offerings in more than one foreign area or culture. 
University of California at Berkeley have tripled theirs. Many new collections are known to have been established in other universities. ..."8 The demands made on many of our institutions by the programs of the Joint Committee on Contemporary China and the establishment of centers for the study of contemporary China by the Ford Foundation at several of our universities have heightened library activity in this vital area. And this comes at a time when identification and procurement of research materials from mainland China have been seriously impeded by the 1959 prohibition on the export of most Chinese language publications.

The Hazard report on the Bibliographical Resources and Needs in the Social Sciences Relating to the Near and Middle East; ${ }^{9}$ the Wilder report on the Acquisition and Control of Publications from the Middle East; ${ }^{10}$ the working papers prepared for the 1957 conference sponsored by the Librarian of Congress and the Committee on South Asia of the Association for Asian Studies set up to examine problems of acquisition, cataloging, and bibliographic needs with respect to American library resources on South Asia; the reports of the Seminars on the Acquisition of Latin American Materials; and the accounts of American library resources for African studies as reported in the African Studies Bulletin, all point up the problems facing our libraries. Common to all or most of these areas are the following:

1. Lack of bibliographical control necessary for the selection of materials;

2. General lack of central or efficient book trade organizations;

${ }^{8}$ G. Raymond Nunn and Tsuen-Hsuin Tsien, "Far Eastern Resources in American Libraries," Library Quarterly, XXIX (January 1959), 29-30.

- Harry W. Hazard, Bibliographical Resources and Needs in the Social Sciences Relating to the Near and Middle East; $A$ Working Paper Based on a Report Mubmitted to the Committee (New York: Social Science Research Council, Committee on the Near and Middle East, 1957)

${ }_{10}$ David Wilder, Acquisition and Control of Publications from the Middle East; $A$ Report Prepared for the Social Science Research Council Committee on the the Social Science Research Council Commind Middle East (New York, 1958).
Neand
3. Lack of systematic book selection policies;

4. Cataloging difficulties resulting from extended programs encompassing materials in a multiplicity of languages;

5. Dearth of selective bibliographical guides to current monographic and serial publications;

6. Problems involved in attracting or training an adequate staff to service area materials;

7. Lack of funds for the purchase, processing, and housing of these materials;

8. Need for up-to-date descriptions of American library resources in each of the areas.

The need for trained librarians with the necessary area, subject, and language competences is fairly obvious. The key library person responsible for the development of the library's area resources should have knowledge not only of the pertinent language or languages, but also of the bibliography of the area, something of the history, literature, and culture of the countries concerned, and of the various means of acquiring materials. The need for joint faculty-library planning and the developing of the resources necessary to sustain the research program calls for a great deal of mutual understanding. The in-service and other training of staff members would also be an important function of the librarian responsible for the area program.

We are faced with a serious problem of staffing our libraries with people adequately qualified to process and service area materials. In many instances, libraries are forced to establish in-service training programs - either by taking people with the necessary language competences and instructing them in library techniques, or by arranging for trained librarians to obtain the desired language backgrounds. In some areas, notably in South Asia, language alone is not sufficient, as is pointed out by H. A. Gleason, Jr., in Varieties of Language Competences: "Each of these many varieties 
of language has its own social value and role. Everyone of them functions as much more than merely a channel of linguistic communication. Their use defines the social situation and so communicates on a different level. Effective use of the language demands not only linguistic competence, but also cultural competence."11 Basic to the problem of recruiting qualified personnel is the need to establish what is the optimum background and training required of people responsible for developing resources for area programs. While beginnings in specialized area librarianship have been made by some of our library schools, much remains to be done. The Joint Subcommittee on Middle East Library Resources of the Joint Committee on the Near and Middle East (ACLS, SSRC, and ARL) has had a draft memorandum prepared on the need for a study which would survey the situation in Middle East centers, identify the education required for area librarians, and explore the possibility of developing the desired curricula cooperatively between area programs and library schools in the same or nearby institutions.

While linguistic competence is a sine qua non, prospective staff members for our area sections, even those who meet the standard qualifications for the positions to which they are assigned, should be offered the opportunity to enrich their language and subject backgrounds by attendance at appropriate courses, seminars, and institutes. The establishment of new programs and the expansion of existing ones should provide opportunities for growth and development for properly qualified librarians. The formation of special area sections within many of our library organizations - many with total responsibility for coordinating faculty-library planning with the selection, acquisition, cataloging, and servicing of the area's research materials-provides

11 In Richard D. Lambert, (ed) Resources for South Asian Area Studies in the United States (Philadelphia: University of Pennsylvania, 1962) p. 104. an increasing number of positions of sufficient responsibility and prestige to attract highly competent people who might otherwise be drawn into teaching and research.

It is obvious that a library which has embarked on a vigorous area program requiring not only the highly trained library specialists but also the added clerical and subprofessional staff will require a substantially higher budget. The everincreasing book budget necessary to sustain current and retrospective purchases is only the beginning of the financial responsibilities incurred by the program. Acquisitions from many sectors of the world will require binding expenses; other materials will be on poor paper requiring either filming for preservation or special handling. The tremendous increase in acquisitions when an area program is started-and almost every survey indicates growth of area resources at a much higher rate than other fields - will present stack problems either immediately or within a short period of time for most libraries. These stack space demands frequently will require extensive and expensive shifting of collections, establishment of new quarters for area programs, or a new central building. In 1956, an additional stack was built at Harvard's former Institute of Geographical Exploration, and part of the building was renovated to insure adequate housing of the Chinese-Japanese library. And Columbia recently moved its four divisions dealing with East Asian studies into new quarters in Kent Hall where, "The East Asian library is to have three times the space for readers that it formerly had, as well as stack space to accommodate the large increase of books anticipated in the coming years."12 Added space for readers and books, whether in separate quarters as in the case of Harvard's and Columbia's Far East libraries, or in spacious quarters in

$$
\text { (Continued on page 304) }
$$

12 East Asian Studies in Columbia University (New York: Columbia University), p. 5. 
The first and most important step and one that is sometimes a bit difficult to accomplish, especially if the material is not to follow a rigidly predetermined pattern, is to prepare an outline in detail and assign a number from the cards to each topic or division. However, changes can be made, values reassigned, and topics added or dropped if material is not available on an anticipated subject or if a different pattern seems more appropriate at a later stage of the research.

The five by eight card, frequently found to be the most convenient size for note taking, has ninety-one numbers that may be assigned to divisions of the outline for direct selection, usually an ample number for most projects. If more divisions are needed, additional numbers in a second row are provided in groups of four, each group permitting up to fourteen classifications or divisions to be added. Obviously the possibilities of selection are more than adequate for almost any conventional undertaking. Around the edge of the card are holes matching the numbers. On any given card, the material in the note determines the holes to be notched out. A quick glance at the master card or the numbered outline indicates the topic or topics that are covered by or related to the note, and holes opposite those numbers are notched out. To select all the material on a given topic or division

\section{Foreign Area Studies}

(Continued from page 296)

a new central library as at Cornell's Olin library, involves both capital outlay and a continuing annual expense.

Also affected by growing area programs is the availability of staff work space, increased reference and circulation work, and the inevitable increase in the number of undergraduate courses in the areas concerned, involving the ob- of the outline, a rod is inserted in the appropriate numbered hole in the stack of cards and is then raised. The cards which drop out because of the previously punched $\mathrm{V}$ notch are those desired.

Because the cards are expensive, costing four or five cents apiece, for notes that require more than both sides of one card, the thrifty scholar can use 4 in. $x$ 6 in. blank tablet sheets, which can readily be fanned slightly on one end, tipped with glue on the fanned edges, and attached to one side of the punched card in such a way as to leave free the selector holes in the edge of the card.

The advantages of this system are chiefly that no cross referring or duplication of notes is necessary because the cross referring and indexing is done by punching the card according to the predetermined plan, either as a note is completed or at the end of a period of note taking when all the notes can be punched at once. If the second method is followed, the conventional headings should probably be made on the card to serve as a guide for punching; or the numbers from the master card or the numbered outline can be jotted down on the card immediately after the note is made. An addition to the advantages already mentioned is the fact that no filing is necessary, for a note is selected by the needle regardless of its location in the stack.

taining of hard-to-get, out-of-print works, journal articles, and necessary duplicate copies of required reading materials.

One gets involved in all these implications when a planned, well-organized program is developed. But what happens when over and above the planned program one has the opportunity of acquiring a large bloc purchase? The processing of such a collection can present problems even to a large library staff with personnel trained and experienced 
in handling area materials. What are the effects of such an acquisition on a library just embarking on an area study program? Can the existing staff manage its processing in a reasonable period of time, or will funds be available to add the necessary help to process the material? If not, the inevitable backlog results. Questions on large block acquisitions include:

1. Does it fit into the long range planning both of the library and the teaching and research staffs?

2. Does it fill an existing gap or is it to be used as the nucleus of a new program?

3. What is required in the way of retrospective purchasing to round out the collection?

4. Can current acquisitions in the field be made without harming established programs?

5. Does the collection contain manuscripts, papers, charts, etc. which might require special facilities for care and preservation, and if so, is the library prepared to handle these special materials?

The recently announced transfer of the Ames library of South Asia to the University of Minnesota where it will be administered as a special unit of the university library is an example of a different, but potentially highly complex block acquisition. This collection of seventyfive thousand items includes books, charts, official papers, and other materials relating to Pakistan, Afghanistan, India, Ceylon, Burma, Tibet, Persia, and Malaya. The interpolation of bibliographical information on a collection of this size into one's catalog could present a substantial problem, to say nothing of the planning which might be required for the coordination of past and future acquisitions with such a substantial collection.

The magnitude of problems incidental to the development of area resources would seem to call for carefully planned programs. Yet Patrick Wilson, ${ }^{13}$ in his survey of South Asian collections, noted the lack of systematic acquisition policies, and Ruggles and Mostecky found ". . . that planned and systematic selection policies, as applied to East European materials . . ., are simply nonexistent in the great majority of research libraries of the United States."14

However, the picture is not completely bleak. The cooperation of librarians and scholars, notably the cooperative efforts of the joint ARL-Farmington Plan-learned societies committees, have made some progress in the following fields:

1. Encouraging descriptive accounts of area resources in individual libraries.

2. The production of bibliographies and research guides.

3. Microfilming projects covering newspapers, archives, and serials.

4. Programs for the reproduction of outof-print books.

5. Cooperative projects including the PL480 programs for the United Arab Republic, India, and Pakistan with the accompanying cooperative and centralized cataloging programs.

6 . The working out of transliteration schemes.

7. The sharing of information via various newsletters and bulletins.

Much more research needs to be done on the problems inherent in the development of non-Western library resourcestheir selection, acquisition, and servicing - and in the training of personnel. Also of primary importance at this time is a study that will explore present practices in the handling of non-Western materials in the major centers with some assessment of the advantages and disadvantages of each. A careful analysis of the experiences of established centers should result in the definition of guidelines applicable to new and changing programs.

${ }^{13}$ Wilson, Survey of South Asian Collections com missioned by Institute of International Studies, University of California, Berkeley (1955).

is Ruggles and Mostecky, op. cit., p. 15. 